\title{
Fuel Filtration New Development Challenges
}

\author{
José Augusto de Oliveira Bazaneli, Bruno de Aguiar, Fábio Moreira, Fernando Jun Yoshino, \\ Marcelo Ney Wood
}

Mahle Metal Leve S/A - Brazil Tech Center

E-mails:

jose.bazaneli@br.mahle.com,bruno.aguiar@br.mahle.com,fabio.mmoreira@br.mahle.com, fernando.yoshino@br.mahle.com,marcelo.wood@br.mahle.com

\begin{abstract}
New regulations like INOVAR AUTO, global development and customer behavior are driving new requirements and technologies. New engines have low fuel consumption, low pollutant emissions, development teams in different countries and low maintenance costs.

As consequence, fuel filtration has also been challenged to new technology levels. Low fuel consumption and low pollutant emission require new technologies like turbo, direct injection and downsizing. These technologies require higher contaminant filtration efficiency for smaller particle size and higher burst pressure to survive in higher fuel pressure lines. Global development teams leads to global specifications and markets. For instance, temperature application range is increased and need to achieve high and low temperature conditions. Maintenance cost is a customer decision making factor. In this way, fuel filters need to have extended dust holding capacity (DHC) to fulfill longer service interval.
\end{abstract}

This paper presents these new market trends and fuel filtration technology directions. New materials, new production process and new product design concept are discussed and a novel fuel filter developed is presented.

\section{INTRODUCTION}

Emission standards for passenger cars are becoming tighter, increasingly demanding fuel economy and reduction of vehicle emissions, forcing the automotive industry to improve their vehicle energy efficiency. The efficiency increase may be obtained by many different ways since drag force reduction and rolling friction reduction.

Focused on engine, there are many ways to increase its efficiency, either by reducing the internal friction losses or making better use of the fuel energy. For harnessing the fuel energy, which means optimize the combustion efficiency, several alternatives are available. One alternative is to increase intake air pressure, temperature and density which may be obtained with forced air induction by using a turbo or compressor charger [1]. Another alternative is to improve the fuel injection process by optimizing the fuel dispersion inside the chamber and/or controlling more precisely fuel injection timing and quantity. To reach these goals the fuel injector is thus placed inside the combustion chamber. These ways to increase engine's efficiency lead the automotive market to technologies as direct injection (DI) and forced 
induction by turbo or compressor charger. Both technologies are already widely used for diesel applications since many years and are becoming also common in ethanol and gasoline applications, especially for new "downsized" cars which are designed with 3 cylinders and usually bring all these technologies together in order to keep the same or better performance allied to the same or smaller fuel consumption when compared to the old 4 cylinders.

It is known that DI brings many benefits related to fuel consumption and power, but on the other hand it also requires a more complex fuel system from the low pressure fuel pump, which has its pressure drastically increased to the fuel injector nozzle. Its diameter is reduced from $500 \mu \mathrm{m}$ to about $170 \mu \mathrm{m}$ depending on the model. As the fuel filter is placed between low pressure fuel pump and fuel injector, it will be directly affected by the pressure increase and will also be responsible to ensure clean fuel to the high pressure pump and fuel injectors.

These demands combined with different fuel mixtures between gasoline and ethanol increase the requirements for fuel filters of flex fuel vehicles. This leads to a new generation of flex fuel filters in order to ensure the proper operation of the DI system, which is presented in this paper.

\section{TECHNOLOGY DRIVER}

\subsection{Efficiency}

The most important task of the fuel filter is to provide clean fuel to the injection system. The main responsible for ensuring the filtering efficiency is the filter media. Commonly for automotive applications the filter media are cellulose paper, non-woven (synthetic) or multi layer combination of cellulose paper and non-woven. There is a wide range of different filter media available to be applied to fuel filters but basically resin-impregnated cellulose papers are used for the majority of applications [2]. Some countries, by instance Brazil, allow that commercial gasoline has hydrous ethanol percentage inside it, besides the $100 \%$ hydrous ethanol commercialization. In such countries the resin used to impregnate cellulose has to be developed in order to be resistant against ethanol and, at the same time, also to protect the cellulose fibers against water attack. In the case the synthetic media, this issue is not considered once they are not affected by water.

While cellulose media are the most common for Otto applications, synthetic or multilayer media are widely used for Diesel applications in order to fulfill the efficiency and water separation requirements. Since the introduction of common rail injection technology, separation efficiency in relation to $4 \mu \mathrm{m}$ particle has now risen from $40 \%$ to more than $98,7 \%$ for cars and 99,7\% for commercial vehicles [3]. In gasoline applications, the work with a filtering efficiency is around $42 \%$ for particles of $5 \mu \mathrm{m}$ and absolute filtration for particles greater than $40 \mu \mathrm{m}$. This difference shows that the diesel system already requires a higher filtering efficiency level compared to the gasoline and shows a potential direction to be followed by the gasoline DI systems.

With the higher filtering efficiency comes the need of higher DHC, because as the efficiency is increased, more particles are retained and more the fuel flow is restricted. 


\section{2}

In order to inject the required volume of fuel during the available timing for the injection, the fuel is pressurized to very high pressure (more than 200 bars). A piston pump is required for multiplying the low pressure and achieving such high pressure. To simplify the high pressure pump construction, the low pressure pump also contributes to increase the fuel pressure [4]. This contribution means to pressurize the fuel up to 7,0 bar instead of 4,5 bar as in the multiport injection (MPI) systems.

With 50\% increase in the low-pressure line, the connectors, hoses and fuel filters need to be redesigned. Furthermore the challenge is not only related to the design and raw material but, in order to be able to work under such pressure, the plastic injection and welding processes are also crucial. Considering that most of the fuel filter is welded during its production, the welding process also needs to be improved. In the case of a polymer fuel filter, the welding quality depends on the welding profile geometry, welding equipment parameters and material properties as mechanical resistance, melting point and fiber content.

\subsection{Environment Resistance}

Due to the benefits of standardization, it has become common the automakers to develop global platforms, and with that comes the global specifications which considers a higher range of temperatures, the most diverse types of contaminants, chemical fluids, fuels and working conditions. In this scenario the challenges are not only related to the filtration technology inside the fuel filter but there is also a challenge outside the filter that is to develop housing materials able to fulfill all the global requirements.

Considering a global platform, the same fuel filter may be applied in a car that will run in the coastal region in the Rio de Janeiro during the summer at $40^{\circ} \mathrm{C}$ or in Moscow during the winter at $-20^{\circ} \mathrm{C}$, for instance. The temperature is just one issue, but in a coastal region there is the sea spray which is very corrosive for metallic parts while the low temperature brings the snow which is not corrosive itself but the Calcium Chloride or Zinc Chloride used to melt the snow may attack some grades of polymers.

\subsection{Maintenance Costs}

Another key factor developing components for the new applications are the driver's behavior and preferences. As the customers are more demanding not only regarding the car performance, design and fuel consumption, but also regarding car depreciation and maintenance costs, furthermore customer have less and less time available to leave the car in the dealer to the periodic maintenance, then a new trend is the automakers to reduce the maintenance costs and/or increase the service interval.

The maintenance costs may be reduced by reducing the price of spare parts or increasing the service interval. Once the fuel cleanliness will not be improved shortly by the fuel suppliers, than the solution to increase the fuel filter service interval optimizes the fuel filter package in order to arrange more filter media in the same package currently available in the applications and as a consequence increase the fuel filter DHC. In order to reduce the price of spare parts, new technologies are being developed as ecological fuel filters in which only the filter element is be replaced. 


\section{NEW CONCEPT DEVELOPMENT}

Since the available space for filtration is limited and the requirements of the automotive industry are constantly increasing, new filter media with higher performance per volume is necessary. For the new fuel injection technologies, which require higher efficiency combined with same or higher DHC, the solution will be a filter media with gradient structures or multi layer structures as showed on figure 1. By implementing these new types in filter media, higher efficiencies and DHC's at low pressure drop can be achieved [2].

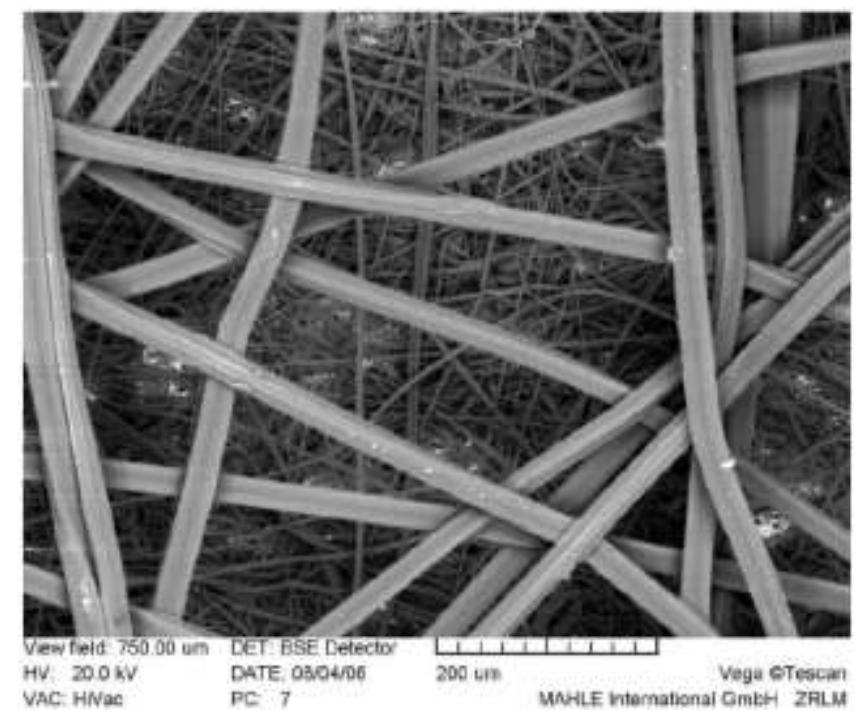

Figure 1. Microscope image of multi layer media [2]

One possible alternative is the nano-fibers media, already available since few years for air filters and currently available for fuel filters. Nano-fibers are a potential option once small fiber diameters result in higher available filtration surface and higher efficiency. The 1000 times scanning electron microscope image showed in figure 2 compares a cellulose media with a synthetic nano-fiber media. It is shown clearly the difference between both media through the advantage of the nano-fiber media for capturing small particles as $2 \mu \mathrm{m}$ and a $5 \mu \mathrm{m}$ diameter particles represented by the red circles.
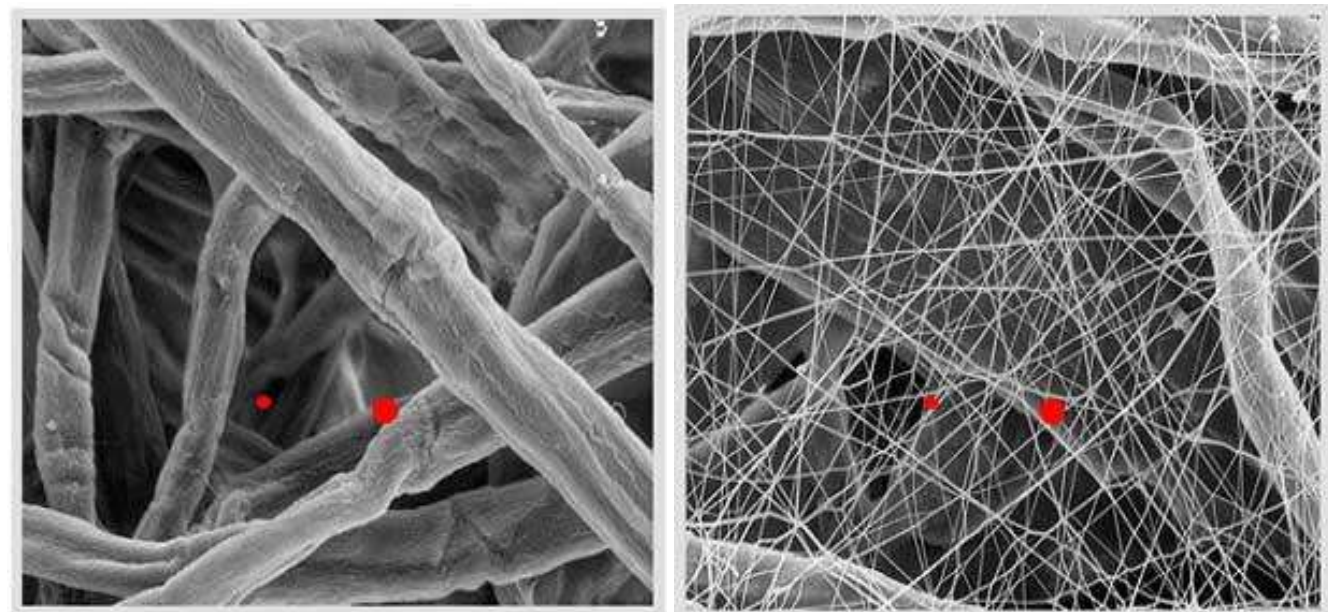

Figure 2. Microscope image of Cellulose filter media (left) and Nano-fiber filter media (right) [5] 
As the water content present in fuel negatively affect some properties of the cellulose media due to the hydrolysis of cellulose and this phenomena does not happens in a synthetic media. Considering that the water will not be totally removed from the fuel easily and including all commented advantages of the non-woven layers as the higher efficiency and DHC, there is a strong tendency of increasing applications of half or fully synthetic filter media for gasoline applications, as it is common for diesel applications.

In a correlation with diesel filters, which are a reference related to filtering efficiency, the diesel filters are recently being developed in polymer aiming cost reduction. It is enhanced due to the recently developed polyamide grades able to fulfill all the validation requirements and present financial savings considering the raw material, tooling and process costs.

The new MAHLE flex fuel filter technology is a polymer fuel filter developed with double layer media. It is focused on increasing the service interval (higher DHC) and facilitating maintenance, while having higher filtering efficiency. The concept is an ecological fuel filter with exchangeable filter element in order to reduce discarded material during fuel filter exchange. This ecological filter was also developed aiming the increase of filtering area in the same filtering package (elimination of quick connectors normally used by conventional filters), as showed by the figure 3 . In this way the service interval increases and the expenses to final customer decreases.

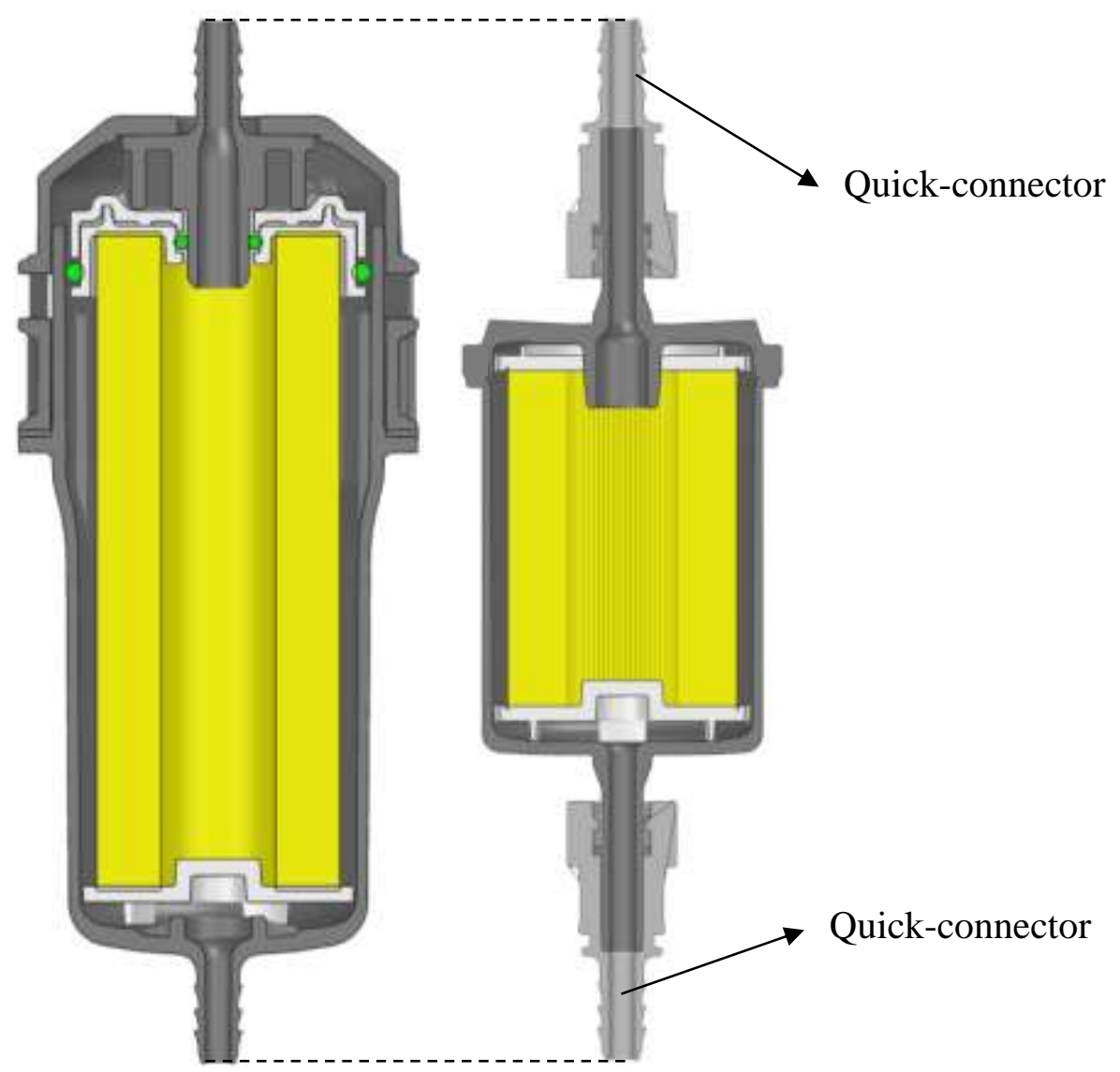

Figure 3. Image of MAHLE ecological fuel filter (left) and convencional fuel filter (right) 
Considering that the fuel filter may be placed at any region of the vehicle even underbody regions susceptible to stones shocks, this new concept has the ability to work under temperatures extremely low, as $-20^{\circ} \mathrm{C}$ or high, as $+70^{\circ} \mathrm{C}$ (not the weather temperature but the environmental temperature wherein the filter may be placed) and stability to keep geometric dimensions even after fuel and temperature aging, achieving now the tendency of global specification from the vehicle manufacturers.

As polymer is a mesoporous material and permeability of vapor and liquids may leads by different mechanisms. The most common mechanisms are diffusion and Knudsen flow [6]. The permeability of polymeric materials affects not only the hydrocarbon emissions but also leads to its destruction and backing its characteristics. So the polymer needs to be carefully selected and analyzed regarding hydrocarbons permeability. This new technology has materials with lower or none hydrocarbons permeability in order to fulfill the most tight emission regulations.

\section{TEST RESULTS}

In order to quantify the performance of MAHLE ecological filter, DHC laboratory tests were done according to ISO 19438 standard. The conventional fuel filter considered in the test is used in the majority of applications in Brazilian market. It was also tested a prototype of MAHLE ecological concept with the same length of the conventional fuel filter and same filter media used by the conventional filter. Finally, MAHLE Ecological filter prototype was tested (multi layer media composed of cellulose and melt blown layers), having it the same length of the conventional fuel filter, too. The test results are showed on figure 4 .

\section{Dust Holding Capacity ISO19438}

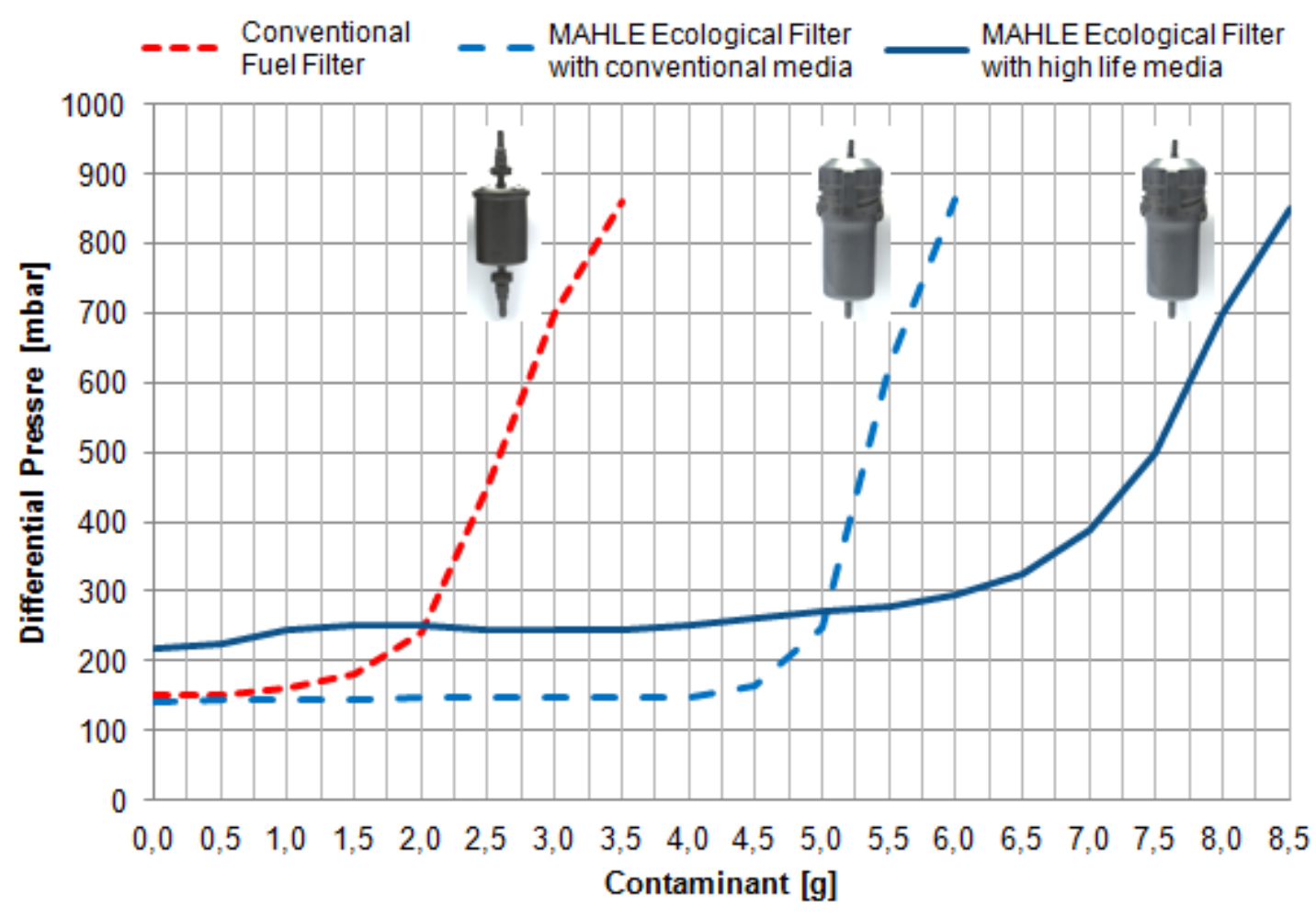

Figure 4. DHC comparison graph 
It is possible to see in the graph that the ecological filter with conventional media presents a higher DHC compared to the current concept. This result was expected once the ecological allow a higher filtering area due to its optimized package, which fits more filter media in the same package currently available for the fuel filter in the vehicles.

MAHLE ecological filter with high life media presented a higher initial flow restriction. This result was expected once the multi layer filter media has two layers and then is thicker compared to the conventional filter media. So there is a higher initial restriction enabling higher filtering efficiency. Thus, the new technology increases the service time interval by almost three times, compared to the conventional flex fuel filters.

In order to summarize the main differences between the conventional filter and the MAHLE Ecological concept, it follows the table 1 below.

Table1. Comparison table between conventional and MAHLE Ecological fuel filter

\begin{tabular}{|c|c|c|}
\hline & Conventional Fuel Filter & MAHLE Ecological Fuel Filter \\
\hline $\mathrm{DHC}$ & $>2 \mathrm{~g} @ 350 \mathrm{mbar}$ & About 3 times higher \\
\hline Efficiency & $42 \%$ for particles $>5 \mu \mathrm{m}$ & At least $10 \%$ higher \\
\hline Serviceability & $\begin{array}{l}\text { Required tools and discard the } \\
\text { whole fuel filter }\end{array}$ & $\begin{array}{l}\text { Tools-free and only filter } \\
\text { element is discarded }\end{array}$ \\
\hline Working Temperature & $\begin{array}{l}\text { Depends on the application } \\
\text { market }\end{array}$ & $\begin{array}{l}\text { Able to work in every region of } \\
\text { the world }\end{array}$ \\
\hline Working Pressure & Up to 5 bar & Up to 7 bar \\
\hline
\end{tabular}

\section{CONCLUSIONS}

In the context of increasingly ecological appeals and the tendency of migration from the multiport injection to the direct injection engines, new technologies are required to ensure the quality of injected fuel. Among these, the filtration system is one of the main attention points involving changes like fuel pressure, fuel filtration efficiency, dust holding capacity requirements, evaporative emissions and others that directly affect the vehicle performance as direct fuel injection and turbo.

Besides the direct injection challenges, the challenges of the fuel filters are not limited to the filtering performance itself, but due to the standardization and globalization of car platforms, there are also challenges in the raw material selection, filter design and construction concept. It is also applied to ecological fuel filter with exchangeable filter element or a new optimized design able to fit more filter media in the current package.

The new ecological flex fuel filter from MAHLE is a novel concept, created to fulfill current multiport injection engines and also direct injection engines having global durability/robustness specifications. As confirmed by laboratory test, this technology is able to increase the filter maintenance time by three times, keeping the same vehicle package space 
existent today. It is also ecological, once only the filter element needs to be replaced, not the entire filter housing, which is the case of conventional filters. Many other benefits and cost reduction to vehicle manufacturer and final customer were also achieved.

\section{REFERENCES}

[1] Simsoo P., "Global Challenge in Innovative Powertrain Pathway for Higher Fuel Economy to 2020 and beyond," 14th Hyundai-Kia International Powertrain Conference (HKIPC) on Oct 28-29, 2014

[2] Siegle S., "Current Challenges in Fuel Filtration," MAHLE Filtersysteme GmbH, Conference - TAE, January, 2007

[3] Markus K., Gunnar-Marcel K., Gunther K., Harald B., Jochen R., "Diesel fuel filters and water separators: "Enabling technology" for the global roll-out of future diesel engines," 36. Internationales Wiener Motorensymposium May, 2015

[4] Fraidl, G.K. ; Piock, W.F. ; Wirth, M., "Gasoline direct injection: Actual trends and future strategies for injection and combustion systems," Society of Automotive Engineers, ISBN 156091-781-4; TRN: IM9638\%\%311

[5] AMSOIL Nano fiber Filter Media and Cellulose Filter Media. Available at: http://www.enhancedsyntheticoil.com/Synthetic_Nanofiber_Filtration.htm (Accessed: 13 May 2016).

[6] Ilya V., Vladimir V., Andrey V., Alexander G., "THE MODELING OF GASOLINE PERMEATION THROUGH NEW POLYMERIC MATERIALS," Fisita 2014 January, 2014

\section{DEFINITIONS/ABREVIATIONS}

DI Direct Injection

MPI Multi Port Injection

DHC Dust Holding Capacity 